\title{
Volume-staged radiosurgery for large arteriovenous malformations: an evolving paradigm
}

\author{
*Zachary A. Seymour, MD, ${ }^{1}$ Penny K. Sneed, MD, ${ }^{1}$ Nalin Gupta, MD, PhD, ${ }^{2,3}$ \\ Michael T. Lawton, MD, ${ }^{2}$ Annette M. Molinaro, PhD, ${ }^{2,4}$ William Young, MD, ${ }^{2,5}$ \\ Christopher F. Dowd, MD,, ${ }^{2,6}$ Van V. Halbach, MD, ${ }^{2,6}$ Randall T. Higashida, MD, ${ }^{2,6}$ and \\ Michael W. McDermott, MD ${ }^{1,2}$
}

Departments of ${ }^{1}$ Radiation Oncology, ${ }^{2}$ Neurological Surgery, ${ }^{3}$ Pediatrics, ${ }^{4}$ Epidemiology and Biostatistics, ${ }^{5}$ Anesthesia, and ${ }^{6}$ Radiology, University of California, San Francisco, California

OBJECTIVE Large arteriovenous malformations (AVMs) remain difficult to treat, and ideal treatment parameters for volume-staged stereotactic radiosurgery (VS-SRS) are still unknown. The object of this study was to compare VS-SRS treatment outcomes for AVMs larger than 10 ml during 2 eras; Era 1 was 1992-March 2004, and Era 2 was May 20042008. In Era 2 the authors prospectively decreased the AVM treatment volume, increased the radiation dose per stage, and shortened the interval between stages.

METHODS All cases of VS-SRS treatment for AVM performed at a single institution were retrospectively reviewed.

RESULTS Of 69 patients intended for VS-SRS, 63 completed all stages. The median patient age at the first stage of VS-SRS was 34 years (range 9-68 years). The median modified radiosurgery-based AVM score (mRBAS), total AVM volume, and volume per stage in Era 1 versus Era 2 were 3.6 versus 2.7, $27.3 \mathrm{ml}$ versus $18.9 \mathrm{ml}$, and $15.0 \mathrm{ml}$ versus 6.8 $\mathrm{ml}$, respectively. The median radiation dose per stage was $15.5 \mathrm{~Gy}$ in Era 1 and $17.0 \mathrm{~Gy}$ in Era 2, and the median clinical follow-up period in living patients was 8.6 years in Era 1 and 4.8 years in Era 2. All outcomes were measured from the first stage of VS-SRS. Near or complete obliteration was more common in Era 2 (log-rank test, $p=0.0003$ ), with 3- and 5 -year probabilities of $5 \%$ and $21 \%$, respectively, in Era 1 compared with $24 \%$ and $68 \%$ in Era 2 . Radiosurgical dose, AVM volume per stage, total AVM volume, era, compact nidus, Spetzler-Martin grade, and mRBAS were significantly associated with near or complete obliteration on univariate analysis. Dose was a strong predictor of response (Cox proportional hazards, $p<0.001, \mathrm{HR} 6.99$ ), with 3- and 5-year probabilities of near or complete obliteration of $5 \%$ and $16 \%$, respectively, at a dose $<17$ Gy versus $23 \%$ and $74 \%$ at a dose $\geq 17$ Gy. Dose per stage, compact nidus, and total AVM volume remained significant predictors of near or complete obliteration on multivariate analysis. Seventeen patients $(25 \%)$ had salvage surgery, SRS, and/or embolization. Allowing for salvage therapy, the probability of cure was more common in Era 2 (log-rank test, $p=0.0007$ ) with 5-year probabilities of $0 \%$ in Era 1 versus $41 \%$ in Era 2. The strong trend toward improved cure in Era 2 persisted on multivariate analysis even when considering mRBAS (Cox proportional hazards, $p=0.055$, HR 4.01, 95\% Cl 0.97-16.59). The complication rate was $29 \%$ in Era 1 compared with $13 \%$ in Era 2 (Cox proportional hazards, not significant).

CONCLUSIONS VS-SRS is an option to obliterate or downsize large AVMs. Decreasing the AVM treatment volume per stage to $\leq 8 \mathrm{ml}$ with this technique allowed a higher dose per fraction and decreased time to response, as well as improved rates of near obliteration and cure without increasing complications. Reducing the volume of these very large lesions can facilitate a surgical approach for cure.

http://thejns.org/doi/abs/10.3171/2014.12.JNS141308

KEY WORDS radiosurgery; AVM; volume-staged radiosurgery; SRS; stereotactic radiosurgery

ABBREVIATIONS ARE = adverse radiation effect; $\mathrm{AVM}=$ arteriovenous malformation; $\mathrm{Cl}=$ confidence interval; CTCAE V4.0 = Common Terminology Criteria for Adverse Events version 4.0; HR = hazard ratio; mRBAS = modified radiosurgery-based AVM score; SM = Spetzler-Martin; SRS = stereotactic radiosurgery; VRAS = Virginia Radiosurgery AVM Scale; VS = volume staged.

SUBMITTED July 17, 2014. ACCEPTED December 9, 2014.

INCLUDE WHEN CITING Published online July 3, 2015; DOI: 10.3171/2014.12.JNS141308.

DISCLOSURE The authors report no conflict of interest concerning the materials or methods used in this study or the findings specified in this paper. Dr. Dowd adjudicated the FRED Trial (MicroVention).

* Drs. Seymour and Sneed contributed equally to this work. 
$\mathrm{S}$ URGERY, embolization, and stereotactic radiosurgery (SRS) are the primary modalities used in the treatment of brain arteriovenous malformations (AVMs). Most AVMs can be treated effectively with acceptable morbidity by using one or all of these modalities. Surgical removal is arguably the best option for small- to mediumsized lesions, defined as Spetzler-Martin (SM) Grades IIII, occurring in noneloquent and superficial regions of the brain, particularly those with a history of hemorrhage. ${ }^{11,21}$ Complete resection is curative and eliminates the risk of hemorrhage without a latent period. Large lesions, usually SM Grades IV and V, have substantially higher surgical complication rates and remain a therapeutic challenge. The overall prevalence or natural history of large AVMs is not well known, but such lesions have also been associated with increased rates of hemorrhage. ${ }^{38}$ In most reports, lesion size is defined by the greatest maximal dimension of the AVM nidus, and the incidence of AVMs larger than $2.5-3 \mathrm{~cm}$ varies from $30 \%$ to $62 \%$ in natural history studies. ${ }^{10}$

Comparing clinical reports of SRS treatment for AVMs to surgical series is not straightforward, as total AVM volume rather than SM grade is the most important factor for SRS risk stratification. ${ }^{5}$ Select small AVMs $(<10 \mathrm{ml})$ have a 3-year obliteration rate of 70\%-95\%..$^{18,27,28}$ Singlesession SRS for the treatment of SM Grade I-II AVMs using a median radiation dose of 22 Gy can have an obliteration rate as high as $90 \%$ at 5 years. ${ }^{16}$ Radiation dose and treatment volume play important roles in the rates of AVM obliteration; Pan et al. reported only a $25 \%$ overall obliteration rate at 40 months for single-stage SRS to treat AVM volumes larger than $15 \mathrm{ml}$ using doses less than 17.5 Gy. ${ }^{25}$ SRS results by SM grade are exceptionally limited for large or higher-risk lesions; one report showed no obliterations in 4 patients with SM Grade V AVM treated in a single session. ${ }^{20}$

Different treatment paradigms for large inoperable AVMs include single-stage SRS, embolization (definitively, pre-SRS, or post-SRS), SRS with planned salvage of surgery or repeat SRS, proton-based SRS, fractionated SRS, dose-staged SRS, and volume-staged (VS)-SRS, which is an alternative approach where the nidus is divided into separate volumes and treated in separate sessions while minimizing overlap between stages. . $^{24,8,9,12,17,19,24,25,34,41,43}$ The factors associated with obliteration following SRS include size and location of the AVM, margin dose, patient age, and prior embolization; pre-SRS embolization may obscure targeting and lower rates of successful obliteration with SRS. ${ }^{2,730}$ Delayed recanalization following embolization may leave up to $15 \%$ of patients susceptible to repeat hemorrhage. In addition, embolization-related neurological complications can occur in 4\%-40\% of patients.., 23

VS-SRS has been described as a way to potentially improve rates of obliteration and decrease the normal tissue $12-$ Gy volume by $27.3 \%$ and the overall $12-$ Gy volume by $11 \%$ compared with a hypothetical single session of SRS. ${ }^{32}$ Volume staging also allows for potentially sublethal damage in normal tissue within the low-dose range to be repaired, theoretically further decreasing the risk of a symptomatic adverse radiation effect (ARE). The rates of obliteration in the VS setting have varied, and predictors of response, such as volume per stage, dose per stage, and AVM architecture, have not been fully defined. ${ }^{2,4,35}$ Multiple scales have been developed to estimate appropriateness of SRS for the treatment of AVMs, such as the modified radiosurgery-based AVM grading system and the Virginia Radiosurgery AVM Scale (VRAS) ${ }^{11,18,22,27,36,37}$ Some or all of these grading systems may be reasonable predictors of outcome, but none have been validated in the VS setting.

Gamma Knife radiosurgery began at our institution in 1991, and we first performed VS-SRS for large AVMs in 1992. In 2004 we prospectively changed the overall treatment paradigm, as a dose-response relationship and predictors of complications became established. ${ }^{5,6,13}$ We shifted to using smaller treatment volumes per stage, shorter intervals between stages, and higher radiation doses per stage. The current review includes all 69 patients with large AVMs who planned to undergo VS-SRS in the period from 1992 to 2008 and compares the outcomes from 2 treatment eras.

\section{Methods}

\section{Patient Selection}

All patients treated with SRS were entered into a prospective database for all treatment characteristics and patient demographics. In this review, all patients with an AVM treated with SRS were retrospectively reviewed and those whose SRS was completed with a volume-staged approach were included in an outcomes data analysis. Prior to referral for SRS evaluation, patients were first reviewed at the weekly multidisciplinary conference attended by neurosurgeons and neurovascular interventional radiologists. Patients were then reviewed at a weekly multidisciplinary conference attended by radiation oncologists, neurosurgeons, neuroradiologists, and a Gamma Knife coordinator. Patients were recommended for a VS approach if AVMs were larger than $10 \mathrm{ml}$ or in nonsurgical locations, or if the patient declined surgery. All patients provided informed consent for treatment. The current retrospective review was approved by the Committee for Human Research at the University of California, San Francisco.

\section{Radiosurgical Technique}

The Leksell Gamma Knife system (Elekta AB) was used to treat all patients. Model B was used from 2000 to 2001, models C and 4C from 2002 to 2007, and the Perfexion model starting in November 2007. Patients underwent imaging with stereotactic cerebral angiography and gadolinium-enhanced MRI and MRA with time-of-flight sequence. Imaging data were imported into GammaPlan software (Elekta $\mathrm{AB}$ ) and used to delineate the target, consisting of the entire AVM nidus on time-of-flight MRI and angiographic registered imaging, without margin. A treatment plan was developed to cover the entire target. The plan was then separated into volumetric stages with attempts to minimize dose overlap between stages, especially outside of the target (Fig. 1). The target was confirmed by a neurosurgeon, neurointerventionalist, and radiation oncologist, and the treatment was approved by the neurosurgeon and radiation oncologist. Dexamethasone, $10 \mathrm{mg}$, was given intravenously on the day of each stage without taper. 


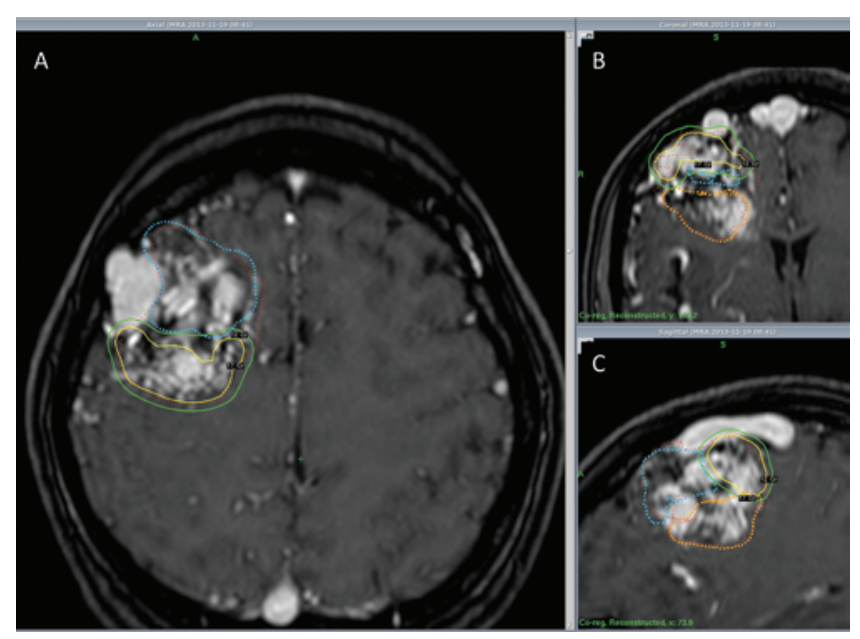

FIG. 1. Example case of VS-SRS from Era 2 in a 22-year-old male with a large frontal AVM with an mRBAS of 5.3 and SM grade of IV. A total of 3 volume stages were completed for a total target volume of $31.78 \mathrm{ml}$. Axial (A), coronal (B), and sagittal (C) MR images of the T1-weighted postcontrast time-of-flight sequence. Figure is available in color online only.

Subsequent stages were completed approximately every 6 months in Era 1 and every 3-4 months in Era 2. New MRI with time-of-flight sequence was performed for each stage to guide target localization. The coregistration of multiple treatment stages was accomplished based on anatomical landmarks and the coregistration capabilities of the GammaPlan software for coordinate transformation. Fig. 1 shows an example of a third stage of treatment with overlays of the prescription dose contours from Stages 1 and 2 . Any changes to initial planned stages were only to align the treatment stage and not to compensate for response, or lack thereof, in the previously treated volume. Some patients in the earliest years had fiducial screw placement in the skull for relocalization with orthogonal films for coregistration between stages for coordinate transformation. ${ }^{26}$

From 1992 to March 2004, defined as Era 1, large AVMs were divided into 2 separate treatment volumes, encompassing approximately $50 \%$ of the nidus in each session, without size limits on the treatment volume per stage. Because the present review spans nearly 2 decades, radiation dose and AVM treatment volume per stage varied based on clinical judgment, AVM size, and AVM location, although doses $>15$ Gy were used when deemed safe. From May 2004 through 2008, defined as Era 2, we prospectively decreased the treatment volume per stage to $\leq 8-10 \mathrm{ml}$, shortened the interval between stages from 6 to 3-4 months, and strongly encouraged prescribing at least 17 Gy.

\section{Patient Follow-Up}

Following the completion of all planned stages, patients were encouraged to undergo yearly brain MRI and cerebral angiography at 3 years. If a residual nidus became safely resectable, patients were counseled regarding the risks and benefits of immediate surgical removal, waiting for possible complete obliteration, or repeat SRS.
Salvage treatment 3-5 years after SRS treatment-either with surgery if the lesion was considered safely resectable to eliminate the latent period or with additional SRS for patients with a large nonresectable, persistent nidus-was recommended in patients with a history of hemorrhage or incomplete obliteration. Complications were scored according to the Common Terminology Criteria for Adverse Events version 4.0 (CTCAE V4.0).

\section{Statistical Analysis}

Each AVM was assigned an mRBAS, VRAS score, and SM grade. ${ }^{27,36,37}$ Lesions were also classified according to angioarchitecture such as the presence of a feeding artery aneurysm, venous restriction, and nidus classification by the treating physician as compact or diffuse.

The total AVM volume and volume per stage were measured by the planning software at the time of treatment. To assess volumetric response in the follow-up period, each lesion was also measured in 3 orthogonal dimensions and the product was divided by 2 at the time of treatment and on follow-up imaging, which was used as a surrogate for lesion volume. Lesion responses were classified as "no response" $(<25 \%$ reduction in nidus volume), "partial response" ( $\geq 25 \%$ reduction), or "near obliteration" $(\geq 75 \%$ reduction) based on MRI or angiography. Complete obliteration was scored only in cases where cerebral angiogram confirmed complete obliteration. ${ }^{31}$ A patient was considered cured if complete obliteration occurred following the initial cycle of VS-SRS or after successful salvage treatment with complete removal or complete obliteration of the nidus, as confirmed on angiography. Adverse radiation effect (ARE) was determined using MRI interpretation and clinical history.

The Wilcoxon rank-sum test was used to assess differences in patient characteristics by dose and era. Given the inherent disparity in follow-up between the 2 cohorts, we assessed survival, hemorrhage, and response over time. End points were measured from the first stage of VSSRS using Kaplan-Meier methodology. Response, cure, and hemorrhage events were assessed with censoring nonevents at the date of the last imaging follow-up, and subsets were compared using the log-rank test. In assessing overall survival, patients were censored on the date of the last clinical follow-up. Univariate and multivariate analyses were completed with Cox proportional hazards models. Multivariate models were evaluated for colinearity between parameters and appropriateness of each model tested. All tests were evaluated at an alpha $=0.05$ level of significance.

\section{Results}

\section{Patient and AVM Characteristics and Treatment Parameters}

There were 38 Era 1 patients and 31 Era 2 patients. See Table 1 for patient and AVM characteristics and treatment parameters. The median age at the time of the first stage was 34 years (range 9-68 years). Of the 149 planned stages in the 69 patients, 143 stages were completed in 63 patients. One patient from Era 1 had a dramatic response to the first stage and was observed instead of recommended 
TABLE 1. Demographics, treatment parameters, salvage, and follow-up by era and prescribed dose

\begin{tabular}{|c|c|c|c|c|c|c|}
\hline Parameter & Era 1 & Era 2 & p Value* & $<17 \mathrm{~Gy}$ & $\geq 17 \mathrm{~Gy}$ & p Value* \\
\hline No. of patients & 38 & 31 & - & 36 (33 in Era 1) & 33 (28 in Era 2) & - \\
\hline No. of patients completing all stages (\%) & $33(87)$ & $30(97)$ & - & $32(89)$ & $31(94)$ & - \\
\hline Median age in yrs (range) & $33(10-68)$ & $35(9-62)$ & 0.96 & $33(10-68)$ & $35(9-62)$ & 0.86 \\
\hline Mean mRS score (range) & $1.24(0-3)$ & $1.29(0-3)$ & 0.72 & $1.21(0-3)$ & $1.31(0-3)$ & 0.54 \\
\hline Prior hemorrhage (\%) & $15(39)$ & $11(35)$ & 0.74 & $14(39)$ & $12(36)$ & 0.83 \\
\hline Prior attempted resection (\%) & $2(5)$ & $2(6)$ & & & & \\
\hline Prior embolization (\%) & $20(53)$ & $5(16)$ & 0.0018 & $19(53)$ & $6(18)$ & 0.003 \\
\hline \multicolumn{7}{|l|}{ Location (\%) } \\
\hline Deep vs cortical only & $14(37)$ & $15(48)$ & 0.34 & $14(39)$ & $15(45)$ & 0.58 \\
\hline Frontal & $23(60)$ & $21(68)$ & & $24(67)$ & $20(61)$ & \\
\hline Temporal & $14(37)$ & $11(35)$ & & $12(33)$ & $13(39)$ & \\
\hline Parietal & $22(58)$ & $14(45)$ & & $22(61)$ & $14(42)$ & \\
\hline Occipital & $9(24)$ & $7(22)$ & & $8(22)$ & $8(24)$ & \\
\hline Thalamus & $10(26)$ & $6(19)$ & & $10(28)$ & $6(18)$ & \\
\hline Basal ganglia & $14(37)$ & $13(42)$ & & $14(39)$ & $13(39)$ & \\
\hline Corpus callosum & $6(16)$ & $5(16)$ & & $6(17)$ & $5(15)$ & \\
\hline Intraventricular & $0(0)$ & $2(6)$ & & $0(0)$ & $2(6)$ & \\
\hline \multicolumn{7}{|l|}{ Angioarchitecture (\%) } \\
\hline Nidal aneurysm & $4(10)$ & $4(13)$ & 0.76 & $4(11)$ & $4(12)$ & 0.90 \\
\hline Feeding artery aneurysm & $2(5)$ & $9(29)$ & 0.0077 & $2(6)$ & $9(27)$ & 0.015 \\
\hline Compact vs diffuse & $17(45)$ & $17(55)$ & 0.41 & $13(36)$ & $21(64)$ & 0.023 \\
\hline Venous restriction & $15(39)$ & $15(48)$ & 0.46 & $14(39)$ & $16(48)$ & 0.43 \\
\hline Deep venous drainage & $29(76)$ & $24(77)$ & 0.91 & $29(80)$ & $24(73)$ & 0.44 \\
\hline SM grade $†$ (\%) & & & 0.0030 & & & 0.0002 \\
\hline III & $4(11)$ & $10(32)$ & & $3(9)$ & $11(34)$ & \\
\hline IV & $14(40)$ & $16(52)$ & & $13(38)$ & $17(53)$ & \\
\hline V & $17(48)$ & $5(16)$ & & $18(53)$ & $4(12)$ & \\
\hline Largest diameter (\%) & & & 0.0014 & & & 0.0001 \\
\hline unknown & $3(8)$ & 0 & & $2(6)$ & $1(3)$ & \\
\hline$\geq 3-6 \mathrm{~cm}$ & $16(42)$ & $26(84)$ & & $14(39)$ & $28(85)$ & \\
\hline$>6 \mathrm{~cm}$ & $19(50)$ & $5(16)$ & & $20(56)$ & $4(12)$ & \\
\hline Eloquence (\%) & $36(95)$ & $28(90)$ & 0.48 & $35(97)$ & $29(88)$ & 0.14 \\
\hline \multicolumn{7}{|l|}{ mRBAS $\ddagger$} \\
\hline Median & 3.6 & 2.7 & 0.0012 & 3.8 & 2.7 & $<0.0001$ \\
\hline Range & $2.3-7.1$ & $1.5-7.8$ & & $2.3-7.8$ & $1.5-5.7$ & \\
\hline$\leq 2$ & $0(0)$ & $4(13)$ & & $0(0)$ & $4(13)$ & \\
\hline $2.01-2.50$ & $2(6)$ & $6(19)$ & & $1(3)$ & $7(22)$ & \\
\hline $2.51-3.00$ & $5(16)$ & $8(26)$ & & $4(13)$ & $9(28)$ & \\
\hline$>3$ & $24(77)$ & $13(42)$ & & $25(83)$ & $12(38)$ & \\
\hline VRAS score (\%) & & & 0.64 & & & 0.54 \\
\hline 2 & $1(3)$ & $3(10)$ & & 0 & $4(12)$ & \\
\hline 3 & $23(60)$ & $17(55)$ & & $23(64)$ & $17(52)$ & \\
\hline 4 & $14(37)$ & $11(35)$ & & $13(36)$ & $12(36)$ & \\
\hline Stages planned (\%) & & & 0.0021 & & & 0.39 \\
\hline 2 & $37(97)$ & $22(71)$ & & $32(89)$ & $27(82)$ & \\
\hline 3 & $1(3)$ & $8(26)$ & & $4(11)$ & $5(15)$ & \\
\hline 4 & 0 & $1(3)$ & & 0 & $1(3)$ & \\
\hline Median dose/stage in Gy (range) & $15.5(12.0-18.0)$ & $17.0(16.0-18.0)$ & $<0.0001$ & $15.5(12.0-16.8)$ & $17.25(17.0-18.0)$ & $<0.0001$ \\
\hline Median total AVM target vol in ml (range) & $27.3(13.5-68.0)$ & $18.9(8.6-65.9)$ & 0.0020 & $29.2(16.2-68.0)$ & $16.8(8.6-50.4)$ & $<0.0001$ \\
\hline Median target vol/stage in ml (range) & $15.0(7.1-38.7)$ & $6.8(4.3-14.5)$ & $<0.0001$ & $15.1(5.2-38.7)$ & $7.0(4.3-11.9)$ & $<0.0001$ \\
\hline Median interval btwn stages in mos (range)§ & $5.8(3.1-31.1)$ & $3.7(2.0-6.7)$ & 0.0003 & $5.8(3.1-31.1)$ & $3.7(2.0-6.7)$ & 0.0007 \\
\hline
\end{tabular}


TABLE 1. Demographics, treatment parameters, salvage, and follow-up by era and prescribed dose (continued)

\begin{tabular}{|c|c|c|c|c|c|c|}
\hline Parameter & Era 1 & Era 2 & p Value ${ }^{*}$ & $<17 \mathrm{~Gy}$ & $\geq 17 \mathrm{~Gy}$ & $p$ Value* \\
\hline \multicolumn{7}{|l|}{ Salvage therapies (\%) } \\
\hline Any & $11(29)$ & $6(19)$ & 0.36 & $10(28)$ & $7(21)$ & 0.53 \\
\hline SRS only & $2(5)$ & 0 & & $2(6)$ & 0 & \\
\hline SRS + embolization or surgery & $6(16)$ & 0 & & $4(11)$ & $2(6)$ & \\
\hline Embolization only & $2(5)$ & 0 & & $2(6)$ & 0 & \\
\hline Surgery only & $1(3)$ & $6(19)$ & & $2(6)$ & $5(15)$ & \\
\hline $\begin{array}{l}\text { Median clinical FU in living patients in yrs } \\
\text { (range) }\end{array}$ & $8.6(0.1-21.5)$ & $4.8(0.2-8.8)$ & 0.035 & $8.3(0.1-21.5)$ & $4.3(0.2-19.4)$ & 0.034 \\
\hline $\begin{array}{l}\text { Median imaging FU in living patients in yrs } \\
\text { (range) }\end{array}$ & $7.2(0-21.4)$ & $4.5(0.1-7.6)$ & 0.044 & $6.5(0-21.4)$ & $3.6(0.1-13.9)$ & 0.021 \\
\hline
\end{tabular}

FU = follow-up; $m R S$ = modified Rankin scale.

* Wilcoxon rank-sum test.

$\dagger$ Missing information in 3 patients.

$\mp$ Missing information in 7 patients.

$\S$ Excluding a 5.4-year interval between Stage 1 and Stage 2 due to insurance and personal issues in 1 Era 2 patient who ultimately completed all 4 planned stages of VS-SRS.

for completion of VS-SRS; the AVM failed to obliterate, and 14 years later the patient eventually had treatment for the remaining nidus volume and later salvage surgery. Four other Era 1 patients failed to complete VS-SRS due to death from an aneurysm hemorrhage $(\mathrm{n}=1)$, loss of insurance $(n=1)$, and loss to follow-up $(n=2)$. One patient from Era 2 with Grade 2 ARE-associated edema declined further treatment.

\section{Response and Obliteration After SRS}

The crude rates of at least partial response, near obliteration only, complete obliteration from initial SRS, and cure allowing for salvage therapy were $58 \%, 11 \%, 13 \%$, and $26 \%$, respectively, for Era 1 compared with 71\%, 29\%, $13 \%$, and $32 \%$, respectively, for Era 2 (Table 2). There were significantly shorter clinical and imaging follow-up periods in living patients in Era 2 (Table 1). When assessing each end point by Kaplan-Meier analysis, there were greater probabilities of at least partial response, near obliteration, and complete obliteration from initial VS-SRS in Era 2 (log-rank test, $\mathrm{p}=0.027,0.0004$, and 0.037; Table 2 and Figs. 2 and 3). Of the 9 patients achieving complete obliteration without salvage therapy, 5 were from Era 1 and 4 were from Era 2. The median time to complete obliteration was 9.9 years for Era 1 versus 4.6 years for Era 2 .

Using a dose of $\geq 17$ Gy per stage was strongly associated with at least partial response and near obliteration $(\log$-rank test, $\mathrm{p}=0.0025$ and $\mathrm{p}=0.0001$; Table 2 and Fig. 4). The 3-year probabilities of at least partial response were $44 \%$ with a dose $<17$ Gy versus $88 \%$ with a dose $\geq 17 \mathrm{~Gy}$, and the 3 -year probabilities of near obliteration were $5 \%$ with $<17$ Gy versus $23 \%$ with $\geq 17$ Gy. Overall rates of complete obliteration were $14 \%$ with $<17$ Gy and $12 \%$ with $\geq 17 \mathrm{~Gy}$, but the median time to complete obliteration was 9.9 years with $<17$ Gy versus 4.6 years with $\geq 17$ Gy. Dose $\geq 17$ Gy was significantly associated with a higher probability of near or complete obliteration (Cox proportional hazards, $\mathrm{p}<0.001$, HR $6.99,95 \%$ CI 2.40-20.32; Table 3).

On univariate analysis, additional factors were asso- ciated with an increased probability of near or complete obliteration, including dose as a continuous variable, total AVM volume, AVM volume per stage, compact nidus, SM grade, and mRBAS (Table 3). Patient age, deep location of the AVM, and prior hemorrhage were not associated with response in this series; however, a trend toward decreased probability of near or complete obliteration was seen with prior embolization $(\mathrm{p}=0.096)$. Time to response was measured from the last treatment, although additional analysis was done to evaluate if the different treatment intervals between eras would result in different outcomes with regard to response. The small differences in timing between the 2 eras, when measured from the first or last treatment, did not alter the results.

Era, dose $\geq 17 \mathrm{~Gy}$, and treatment volume per stage were not evaluated together in multivariate analyses, as these parameters were highly correlated with one another. Each of these factors is a surrogate for the era (see Table 2), and the inclusion of any of the 3 factors independently did not alter the outcome of the multivariate analysis. The mRBAS was not evaluated with total AVM volume, as this is a factor within the scale. On multivariate analysis of near or complete obliteration evaluating total AVM volume, dose $<17$ Gy versus $\geq 17$ Gy, and compact architecture, all 3 parameters remained significant (Table 4). In addition, when evaluating multivariate analysis with mRBAS, the results did not change; mRBAS was still a significant predictor of response ( $\mathrm{p}=0.013$, HR $0.55,95 \%$ CI $0.34-0.88$ ). History of prior embolization was not a significant factor, nor did it become significant with inclusion in any multivariate model evaluated.

\section{Salvage Therapy and Cure}

Seventeen patients underwent 1 or more salvage therapies at a median of 56.0 months (range 22.5-169.2 months for the first or only salvage treatment). Eight patients had salvage SRS at a median of 61.8 months (range 46.3-169.2 months), and 12 patients had salvage surgery at a median of 73.9 months (range 22.5-223.9 months). Of the 20 patients who were cured, 9 were cured with salvage surgery 
TABLE 2. Outcomes by era and prescribed dose*

\begin{tabular}{|c|c|c|c|c|c|c|}
\hline End Point & Era $1(n=38)$ & Era $2(n=31)$ & p Value & $<17$ Gy $(n=36)$ & $\geq 17$ Gy $(n=33)$ & $\mathrm{p}$ Value $\dagger$ \\
\hline \multicolumn{7}{|c|}{ At least partial response } \\
\hline Crude & 58 & 71 & \multirow[t]{3}{*}{0.027} & 56 & 73 & \multirow[t]{3}{*}{0.0025} \\
\hline 3 yrs & $46(30-66)$ & $87(71-97)$ & & $44(28-65)$ & $88(72-97)$ & \\
\hline $5 \mathrm{yrs}$ & $71(52-87)$ & $92(76-99)$ & & $70(50-87)$ & $92(77-99)$ & \\
\hline \multicolumn{7}{|l|}{ Near obliteration only } \\
\hline Crude & 11 & 29 & \multirow[t]{3}{*}{0.0004} & 8 & 30 & \multirow[t]{3}{*}{0.0001} \\
\hline 3 yrs & $5(1-28)$ & $24(11-49)$ & & $5(1-28)$ & $23(10-47)$ & \\
\hline $5 \mathrm{yrs}$ & $21(8-46)$ & - & & $16(5-41)$ & - & \\
\hline \multicolumn{7}{|l|}{ Complete obliteration } \\
\hline Crude & 13 & 13 & \multirow[t]{3}{*}{0.037} & 14 & 12 & \multirow[t]{3}{*}{0.13} \\
\hline 3 yrs & 0 & 0 & & 0 & 0 & \\
\hline $5 \mathrm{yrs}$ & 0 & $13(3-41)$ & & 0 & $13(3-41)$ & \\
\hline \multicolumn{7}{|c|}{ Near or complete obliteration } \\
\hline Crude & 24 & 42 & \multirow{3}{*}{0.0003} & 22 & 42 & \multirow{3}{*}{0.0001} \\
\hline 3 yrs & $5(1-28)$ & $24(11-49)$ & & $5(1-28)$ & $23(10-47)$ & \\
\hline $5 \mathrm{yrs}$ & $21(8-46)$ & $68(46-88)$ & & $16(5-41)$ & 74 (52-92) & \\
\hline \multicolumn{7}{|c|}{ Cure allowing for salvage } \\
\hline Crude & 26 & 32 & \multirow[t]{3}{*}{0.0007} & 25 & 33 & \multirow[t]{3}{*}{0.0073} \\
\hline 3 yrs & 0 & $11(3-37)$ & & $5(1-32)$ & $5(1-29)$ & \\
\hline $5 \mathrm{yrs}$ & 0 & $41(22-67)$ & & $5(1-32)$ & $35(17-61)$ & \\
\hline \multicolumn{7}{|c|}{ Hemorrhage after SRS } \\
\hline Crude & 29 & 23 & \multirow[t]{3}{*}{0.77} & 33 & 18 & \multirow[t]{3}{*}{0.31} \\
\hline 3 yrs & $27(14-47)$ & $24(11-46)$ & & $31(17-51)$ & $19(8-40)$ & \\
\hline $5 \mathrm{yrs}$ & $31(17-52)$ & $24(11-46)$ & & $35(20-56)$ & $19(8-40)$ & \\
\hline \multicolumn{7}{|l|}{ Survival } \\
\hline Crude & 79 & 87 & \multirow[t]{3}{*}{0.57} & 75 & 91 & \multirow[t]{3}{*}{0.19} \\
\hline 3 yrs & $88(70-95)$ & $89(69-96)$ & & $84(66-93)$ & $93(74-98)$ & \\
\hline $5 \mathrm{yrs}$ & $80(60-91)$ & $84(63-94)$ & & $76(56-88)$ & $88(68-96)$ & \\
\hline \multicolumn{7}{|l|}{ SRS complications } \\
\hline Crude & 29 & 13 & \multirow[t]{3}{*}{0.23} & 28 & 15 & \multirow[t]{3}{*}{0.43} \\
\hline $1 \mathrm{yrs}$ & $12(5-29)$ & $7(2-26)$ & & $12(5-29)$ & $7(2-25)$ & \\
\hline $3 \mathrm{yrs}$ & $30(17-50)$ & $11(4-31)$ & & $27(14-47)$ & $15(6-35)$ & \\
\hline
\end{tabular}

* Values are expressed as percentages with their $95 \%$ confidence intervals.

$\dagger$ Log-rank test.

and 2 with salvage SRS and surgery combined (Table 1). Crude rates of cure were 26\% in Era 1 and 32\% in Era 2. Four additional patients (1 from Era 1 and 3 from Era 2) with partial $(n=1)$ or near $(n=3)$ obliteration on MRI declined to undergo angiographic evaluation and/or curative surgery. The median time to cure was 9.1 years for 10 patients from Era 1 (range 5.1-18.4 years) compared with 3.9 years for 10 patients from Era 2 (range 1.9-7.6 years). The actuarial probability of cure was significantly improved in Era 2 (log-rank test, $\mathrm{p}=0.0007$; Table 2 and Fig. 5) with a 5 -year probability of $0 \%$ for Era 1 versus $41 \%$ for Era 2. Cure was also associated with SRS dose, with 5-year probabilities of 5\% for a dose < 17 Gy versus $35 \%$ for a dose $\geq 17$ Gy (log-rank test, $p=0.0073$ ). Using multivariate analysis to adjust for mRBAS, there was a trend toward a higher probability of cure in Era $2(\mathrm{p}=0.055$, HR 4.01, 95\% CI 0.97-16.59).

\section{Complications After VS-SRS}

A total of 15 patients experienced 18 radiation-induced symptomatic neurological complications, including 11 temporary and 7 persistent complications. Three patients had CTCAE V4.0 Grade 3 toxicity, but none experienced Grade 4 toxicity or higher. The most common complication was temporary ARE-associated headache and swelling, which occurred in 7 patients. Visual field cut occurred in 5 patients, which was most commonly a quadrantanopia, and resolved in 2 patients with the use of steroids. Mild worsening of baseline hemiparesis occurred in 3 patients, which ultimately resolved with the use of steroids in 2 patients. One of the 3 patients developed new-onset seizures that were stabilized by medications, one patient developed aphasia with chronic steroid dependence at last follow-up, and one patient developed symptomatic radiation-induced cyst. Two additional patients developed an asymptomatic radiation-induced cystic change that required no intervention, remained stable during follow-up imaging, and was not counted as a complication. Of the 12 patients treated with salvage surgery, none experienced significant postsurgical complications. 


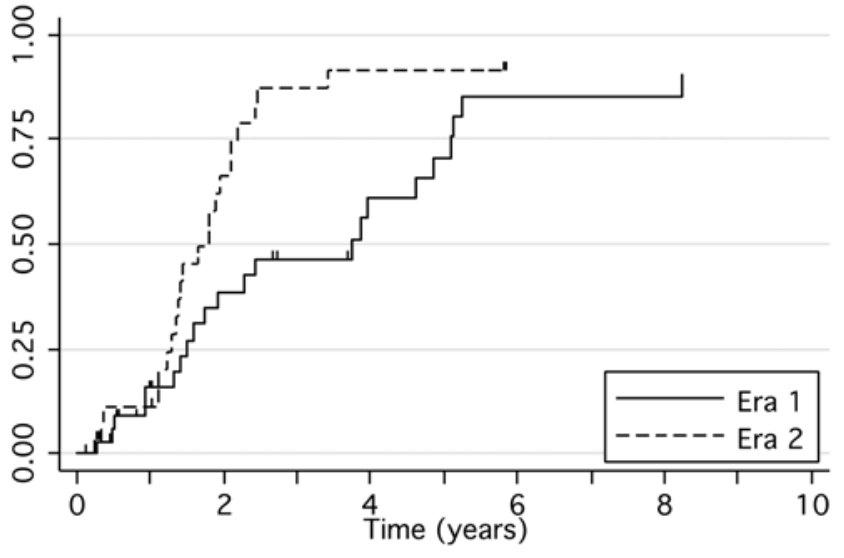

FIG. 2. Time to at least partial ( $\geq 25 \%$ ) obliteration of the nidus measured from the first stage of VS-SRS in all patients, comparing 2 treatment eras.

The overall complication rate was $29 \%$ in Era 1 compared with $13 \%$ in Era 2. Persistent complications occurred in $16 \%$ of Era 1 patients versus 3\% of Era 2 patients. Actuarial risk of complications or persistent complications was not significantly different when evaluating by era, dose, or overall volume.

\section{Hemorrhage and Survival After VS-SRS}

Hemorrhage occurred on 23 occasions in 18 patients after VS-SRS; 11 patients experienced 15 hemorrhages in Era 1, and 7 patients experienced 8 hemorrhages in Era 2. The rate of mortality per bleed was $39 \%$. With 411 patient years of follow-up, there was a 5.6\% annual risk of hemorrhage. Assuming a $7 \%$ risk of repeat hemorrhage in the 1st year after a hemorrhage and otherwise a $4 \%$ annual risk, we would have estimated 16.8 hypothetical post-SRS hemorrhage events compared with 23 actual hemorrhage events.

There were 12 deaths, including 8 Era 1 patients and 4 Era 2 patients. Nine patients died from AVM-related hemorrhage, 1 patient died of an untreated cerebral artery aneurysm, 1 patient died of a seizure disorder that was present prior to VS-SRS, and 1 patient died of unknown

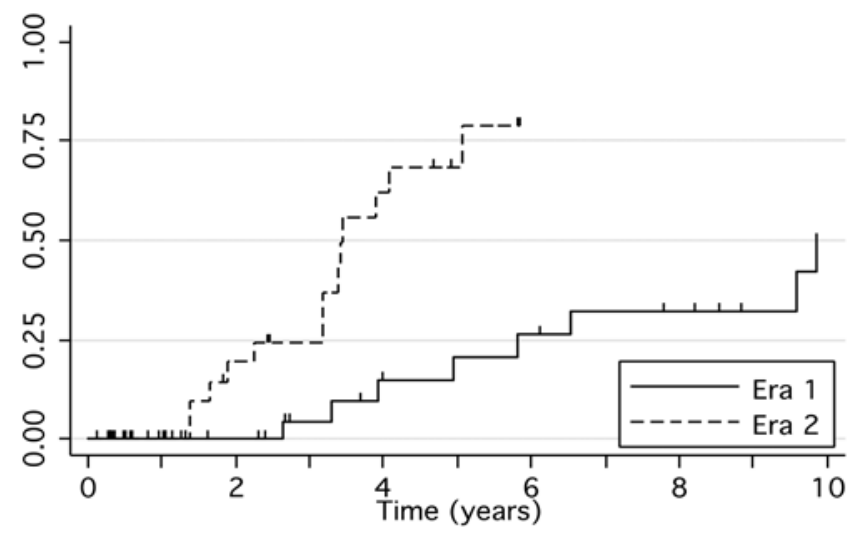

FIG. 3. Time to near $(\geq 75 \%)$ or complete obliteration of the nidus measured from the first stage of VS-SRS in all patients, comparing 2 treatment eras.

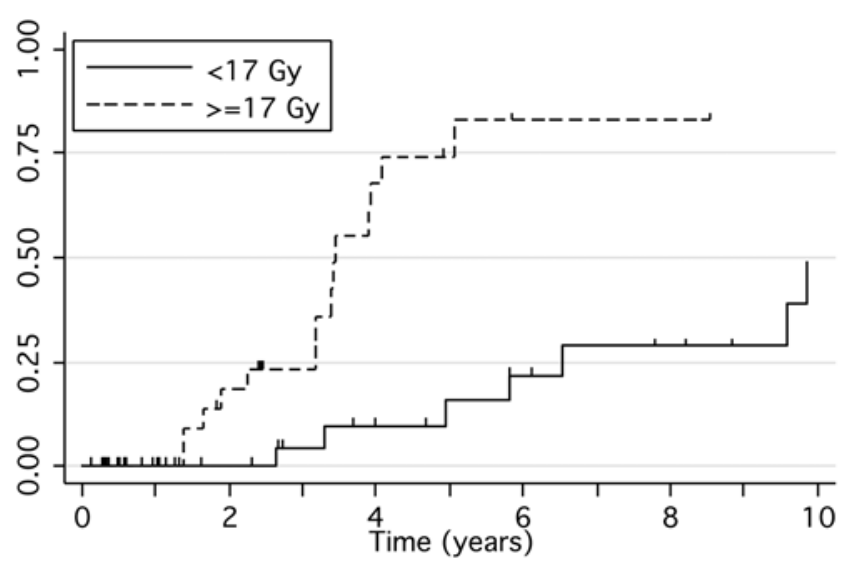

FIG. 4. Time to near ( $\geq 75 \%$ ) or complete obliteration of nidus measured from the first stage of VS-SRS in all patients, comparing 2 dose levels (< 17 Gy vs $\geq 17$ Gy).

causes. There were no significant differences in survival times or freedom from hemorrhage for Era 1 versus Era 2 or for a dose $<17$ Gy versus $\geq 17$ Gy (Table 2 and Fig. 6).

\section{Discussion}

\section{Results of Non-VS-SRS Approaches for Large AVMs}

Obliteration of large AVMs with acceptable morbidity remains a therapeutic challenge. There are many treatment options for these large lesions without an accepted gold standard. Currently, without a preponderance of data to guide practitioners in how to optimize outcomes and minimize complications, all treatment options may be reasonable approaches in select patients.

Hattangadi et al. reported a $15 \%$ overall obliteration rate at a median of 62.5 months after proton-based SRS for large AVMs with a median volume of $22.9 \mathrm{ml} .{ }^{12}$ Among 31 patients with AVMs $>10 \mathrm{ml}$ who were treated with dose-staged Gamma Knife radiosurgery (with a planned second dose of 12-16 Gy to the residual nidus 3 years after initial SRS), 26 patients received a second dose stage and 7 received a third dose stage; there was one obliteration after the first stage. Complete obliteration occurred in 16 of 21 evaluable patients, but for almost all patients this approach required at least 6 years before obliteration was achieved..$^{42}$ With hypofractionated linear accelerator (LINAC)-based treatment of $5 \mathrm{~Gy} \times 6$ fractions, the overall obliteration rate was $22 \%$ in 18 evaluable patients after 5 years of follow-up study, but the rate was only $8 \%$ among patients with a $>$ 14-ml residual nidus after pre-SRS embolization. ${ }^{41}$

\section{Results of VS-SRS for Large AVMs}

Kano et al. retrospectively reviewed 47 patients treated with VS-SRS for large AVMs and found a strong association on univariate and multivariate analyses for an improved response with an increasing dose $(\geq 17 \mathrm{~Gy}) .{ }^{13}$ The overall obliteration rate in their study was $23 \%$ for initial VS-SRS with $7 \%$ and $28 \%$ probabilities of obliteration at 3 and 5 years. Among patients treated with $\geq 17 \mathrm{~Gy}$, however, the rate of obliteration including salvage therapy improved to $62 \%$ at 5 years. The overall obliteration rate in 
TABLE 3. Univariate analysis for near or complete obliteration

\begin{tabular}{|c|c|c|c|c|}
\hline \multirow[b]{2}{*}{ Parameter } & \multicolumn{2}{|c|}{ Near or Complete Obliteration } & \multicolumn{2}{|r|}{ Cure } \\
\hline & $p$ Value $^{*}$ & $\mathrm{HR} \dagger(95 \% \mathrm{Cl})$ & p Value* & $\mathrm{HR} \dagger(95 \% \mathrm{Cl})$ \\
\hline Age \# & 0.74 & $1.01(0.97-1.04)$ & 0.72 & $1.01(0.97-1.04)$ \\
\hline $\operatorname{Sex}(0=F ; 1=M)$ & 0.40 & $0.69(0.30-1.62)$ & 0.92 & $1.05(0.43-2.56)$ \\
\hline Era 1 vs 2 & 0.001 & $5.82(2.02-16.80)$ & 0.003 & $7.82(2.00-30.62)$ \\
\hline Total AVM vol & 0.004 & $0.93(0.88-0.98)$ & 0.053 & $0.96(0.91-1.00)$ \\
\hline AVM vol per stage & $<0.001$ & $0.74(0.63-0.87)$ & 0.001 & $0.81(0.72-0.92)$ \\
\hline Dose per stage & $<0.001$ & $2.54(1.53-4.21)$ & 0.002 & $1.91(1.26-2.87)$ \\
\hline Dose $\geq 17$ Gy (0 = no; 1 = yes) & $<0.001$ & $6.99(2.40-20.32)$ & 0.011 & $3.66(1.35-9.95)$ \\
\hline Prior hemorrhage ( $0=$ no; $1=$ yes $)$ & 0.93 & $0.96(0.38-2.38)$ & 0.63 & $1.25(0.49-3.18)$ \\
\hline Prior embolization ( $0=$ no; 1 = yes) & 0.096 & $0.45(0.17-1.15)$ & 0.68 & $1.21(0.48-3.06)$ \\
\hline Compact nidus ( $0=$ no; $1=$ yes $)$ & 0.005 & $4.17(1.53-11.37)$ & 0.18 & $1.92(0.73-5.01)$ \\
\hline Location ( 0 = cortical only; 1 = deep $\ddagger$ ) & 0.44 & $1.40(0.60-3.26)$ & 0.25 & $0.57(0.21-1.50)$ \\
\hline SM grade & 0.017 & $0.51(0.29-0.88)$ & 0.44 & $0.79(0.44-1.43)$ \\
\hline mRBAS & 0.005 & $0.49(0.30-0.81)$ & 0.028 & $0.58(0.36-0.94)$ \\
\hline VRAS score & 0.42 & $0.73(0.34-1.57)$ & 0.78 & $1.11(0.52-2.38)$ \\
\hline
\end{tabular}

their high-dose subset was higher than would be predicted by mRBAS. Our study, which represents the largest review of VS-SRS for AVM to date, reveals slightly lower overall rates of obliteration, particularly notable in Era 1, with $0 \%$ obliteration by 5 years after treatment. This poor rate of response provided the impetus for us to prospectively change our treatment paradigm. Our $68 \%$ and $41 \%$ 5-year probabilities of near or complete obliteration and cure, respectively, for Era 2 are more in line with the results reported by Kano et al.

\section{Definition of Obliteration}

The definition of obliteration in most reviews is based on either MRI or angiographic obliteration and may overestimate the rate of cure, as obliteration on MRI is $84 \%$ predictive of obliteration on angiography. ${ }^{31}$ Hemorrhage has been noted in patients with only MRI-confirmed obliteration, suggesting that these lesions may still have hemorrhagic potential. ${ }^{37}$ Our practice of obtaining an angiogram after 3 or more years and requiring angiographic confirmation of obliteration, rather than MRI confirmation alone, may artificially lower our rates of complete obliteration and cure. In addition, 2 patients in Era 2 with near

TABLE 4. Multivariate analysis for near or complete obliteration

\begin{tabular}{lcc}
\hline \multicolumn{1}{c}{ Parameter } & p Value* & HR† (95\% Cl) \\
\hline Total AVM vol & 0.014 & $0.94(0.90-0.99)$ \\
\hline Dose $\geq 17$ Gy $(0=$ no; $1=$ yes $)$ & 0.010 & $5.34(1.50-18.95)$ \\
\hline Compact nidus $(0=$ no; $1=$ yes $)$ & 0.045 & $2.87(1.02-8.04)$ \\
\hline * Cox proportional hazards model. & & \\
$\dagger$ \\
tion.
\end{tabular}

obliteration on MRI declined to undergo angiographic evaluation, and if not cured, they would appear to be good candidates for surgical removal of the residual nidus.

\section{Predictors of Response}

Radiation dose, compact nidus architecture, and total AVM volume appear to be important factors in predicting response, and they remained significant in appropriate multivariate models. A dose $\geq 17$ Gy was associated with a 5-fold increase in the likelihood of near or complete obliteration on multivariate analysis. Era and dose are irrevocably intertwined in this series, although the persistent nature of dose as the most important factor for response, even when considering total AVM volume, suggests that further volume staging with higher doses per stage may have benefitted patients in Era 1.

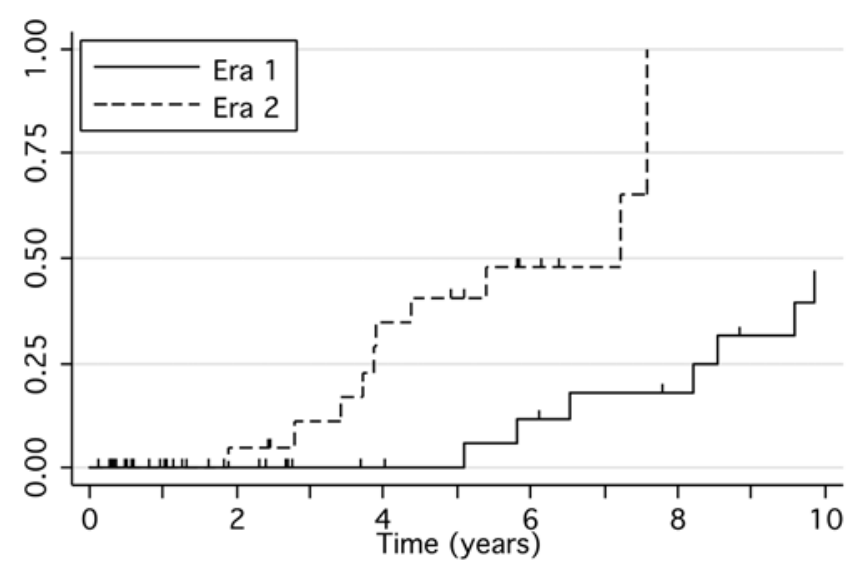

FIG. 5. Time to cure, allowing for salvage therapy, measured from the first stage of VS-SRS in all patients, comparing 2 treatment eras. 


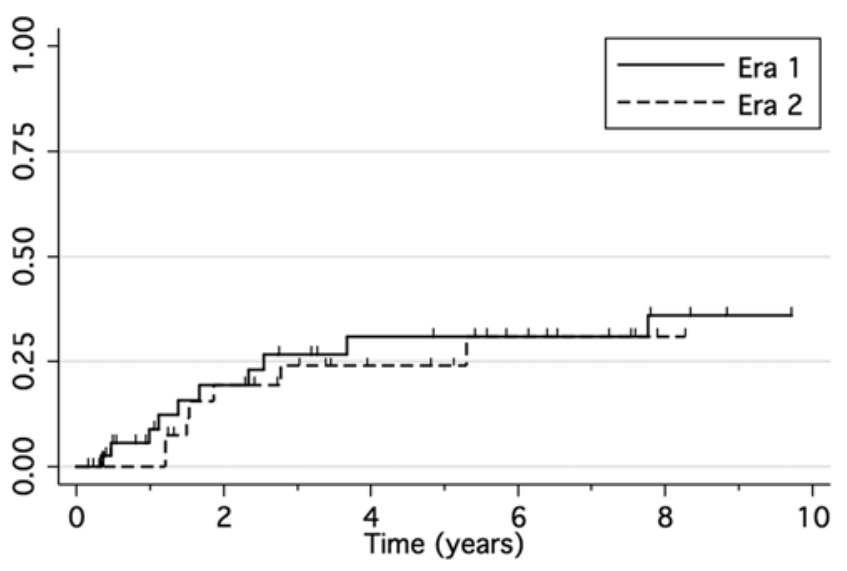

FIG. 6. Time to first hemorrhage post-SRS from the first stage of VSSRS in all patients, comparing 2 treatment eras.

Our findings agree with previous reports that a higher margin dose is a strong predictor of response in a given AVM. ${ }^{16}$ Kano et al. noted improved responses in the VS setting with doses of $\geq 17$ and $\geq 18$ Gy, suggesting a continued dose-response curve. ${ }^{13}$ Flickinger et al. modeled dose responsiveness of AVM obliteration and did not find diminishing responsiveness until $\geq 23 \mathrm{~Gy}$. $^{6}$ These findings suggest that further volume staging may improve response by allowing higher doses, possibly $\geq 18$ Gy per stage, along with a smaller volume per stage and increased number of stages. It may also be possible to improve outcomes in even smaller lesions than those reported here with the use of volume staging.

A cohort comparison, as in this analysis of nonrandomized historical cohorts, has inherent limitations. Given the changes in management over time, such as a growing reluctance to embolize, increased experience with SRS for $\mathrm{AVM}$, improved imaging and treatment planning techniques, a patient base with more moderately sized AVMs, and more aggressive use of salvage therapy, the cohorts were not balanced. Most of these factors, other than total AVM volume and possibly embolization, are unlikely factors to predict greater volumetric reductions observed in Era 2 and with doses $\geq 17$ Gy. Furthermore, the multivariate analysis of at least near obliteration suggests that the differences, including total AVM volume and prior embolization, were less important factors than dose per stage and compact nidal architecture. Increased dose per stage was also significantly associated with an increased probability of cure ( $\mathrm{p}=0.011$, HR 3.66, 95\% CI 1.35-9.95).

Another limitation of this evaluation is the use of near or complete obliteration, a relative volumetric-based response, and cure as end points rather than obliteration. This limitation is partly attributable to the use of surgery as salvage treatment in this series, which was employed to limit the latent period in select patients. Almost all series that estimate the rate of total obliteration after SRS allow for SRS salvage, which may artificially increase the probability of obliteration. The probability of complete obliteration from initial SRS for large AVMs in all retrospective reviews is low. Most patients will be candidates for salvage therapy, as partial response may not reduce the risk of hemorrhage in the latent period. However, decreasing volume of the residual nidus prior to salvage therapy is a reasonable goal, and increasing the volumetric response could speed the time to safe surgical salvage, as AVM size is associated with response, hemorrhage, and complications in either initial or retreatment settings. ${ }^{14,20,28,37}$

\section{Salvage Therapy and Cure}

Assessment of cure for large AVMs is complicated, as most patients will not be cured. Obliteration is a delayed phenomenon, and outcomes may be confounded by salvage therapy, which has been reported to affect the probability of complete obliteration in nearly all reviews. Surgery, which remains the gold standard for safely resectable lesions, has been used with good outcomes in the salvage setting for initially unresectable AVMs. ${ }^{1,33}$ Radiosurgery reduces the volume of the nidus as well as possibly the operative morbidity in previously unresectable lesions. Our goal is, in part, to facilitate surgery since most patients will not experience obliteration after VS-SRS, which has been demonstrated in all series on these large lesions, or patients will experience obliteration only in a protracted manner. Partially obliterated lesions may not have a lower risk of hemorrhage, but increasing the dose per stage may allow for a reduced latent period from initial therapy, reduce the volume at the time of salvage therapy, and potentially decrease the time to salvage surgery, which would eliminate the latent period.

In our series, crude rates of cure were similar in each era, but with a significantly shorter time to cure in Era 2 ( $p$ $=0.0007)$. Surgical salvage was involved in the treatment of 11 of 20 patients achieving cure, reinforcing the need for multimodality care for many of these patients. The fact that none experienced significant complications related to their resection suggests that changes related to SRS and volumetric reduction in the nidus may improve the safety and efficacy of resection. ${ }^{39}$ Currently, there are no established guidelines for salvage therapy. Given the very high rate of salvage therapy necessary to cure patients with large AVMs, evaluation of cure alone may underestimate changes in response to the initial modality of care, as patterns of salvage therapy change over time. The ideal time for surgery after SRS is unknown, but within this series the practice of salvage surgery appeared to be safe at more than 3 years after VS-SRS.

\section{Models Predicting Response}

In our series, even when adjusting for mRBAS, there was a strong trend toward improved rates of cure in Era $2(\mathrm{p}=0.055$, HR 4.01, 95\% CI 0.97-16.59) despite a median follow-up of only 4.8 years, a period when we would expect many patients to just start achieving obliteration. This suggests that cure was more likely when controlling for the most dominant factors affecting response and cure, including overall AVM volume, patient age, and AVM location. In many respects, it may not be appropriate to assess patients treated with VS-SRS by using the mRBAS, VRAS score, or SM grade. The SM grade was based on retrospective analysis of surgical toxicity outcomes in patients thought to be curable through surgery, and mRBAS and VRAS score have only been assessed in single-session 
SRS with an end point of complete obliteration rather than degree of response. ${ }^{11,27,37}$ Size is the dominant driving factor in all models to date and is undoubtedly a very important prognostic factor, but volume-staging allows disassociation of total volume and prescribed dose. Grading scales associated with single-session SRS and surgery will need to be reevaluated in the VS setting. Higher response rates were achieved in these large AVMs than would be expected by mRBAS alone ${ }^{20}$ and the mRBAS appeared to be a reasonable predictor of response and cure in this series. The size stratification of the VRAS score, while being an excellent predictor of cure for small- to medium-sized AVMs near the cutoff of $4 \mathrm{ml}$ for the highest-risk group, may limit its application to larger AVMs.

\section{Complications}

Complication rates in this study appear similar to those in other published series of large AVMs treated with SRS, which range from $10 \%$ to $43 \% .^{12}$ In a series by Vernimmen et al., there was a $23 \%$ risk of transient AREs and a $6 \%$ risk of persistent late effects following proton therapy for AVM, including $43 \%$ of patients with lesions $>14$ $\mathrm{ml} .{ }^{39}$ Blackburn et al. reported $20 \%$ persistent neurological deficits related to embolization followed by single-session SRS for large AVMs, though this included aggressive embolization prior to SRS and the median residual volume was only $8.9 \mathrm{ml}^{3}{ }^{3}$ Our complication rate also appeared lower than that in the largest recent series by Veznedaroglu et al. on LINAC-based SRS using $7 \mathrm{~Gy} \times 6$ fractions, which resulted in an $83 \%$ obliteration rate in the high-dose group but a $43 \%$ risk of Grade 4 toxicity overall, requiring dose de-escalation to 30 Gy and inferior outcomes ${ }^{40}$ Pan et al. also reported a $37 \%$ moderate ARE and a $12 \%$ severe ARE with single-session SRS at median doses of 17.7 Gy for AVM volumes of 10-20 ml and 16 Gy for volumes $>20 \mathrm{ml} .{ }^{25}$ While dose-staging as reported by Yamamoto et al. was associated with only a $6.5 \%$ complication rate, there was a hemorrhage rate of $22.6 \%$ due to an extended latent period (similar to the hemorrhage risk in our series). ${ }^{42}$ Comparison with surgical series is tenuous due to patient selection bias, but risks of major neurological complications after resection have been reported to be $21.6 \%$ and $16.7 \%$ for SM Grades IV and V, respectively. ${ }^{11}$ Even selected patients with SM Grade III AVMs that are large and in eloquent regions have a $14.8 \%$ risk of neurological deficit after resection. ${ }^{21}$

With a VS approach, the ideal timing between fractions is unknown, but this study shows that a reduction in the interval between stages to 3 months appears safe with the dose staging described. An increased interval may only delay obliteration without increasing safety, and a reduction in the interval may not allow for an asymptomatic treatment response to dissipate and may lead to more issues with AREs when treatments are delivered in short succession.

\section{Hemorrhage and Survival}

Despite improved time to response and cure rates in Era 2 , the overall rates of survival and hemorrhage were not different between the 2 eras. The rate of post-SRS hemorrhage was high. It is unclear if the high rate of hemor- rhage was related to a natural predilection for hemorrhage in these large AVMs, patient selection, or short interval follow-up around the time of previous hemorrhage. We did not have adequate imaging data to account for all risk factors for hemorrhage prior to treatment, such as the number of draining veins, to fully estimate the risk of hemorrhage for comparison with other reports. Reviews of single-session SRS for AVM have suggested a stable or decreased overall risk of hemorrhage after SRS, such as reported by Yen et al. in 1400 AVM patients with an annual hemorrhage risk of $2.5 \%$ following SRS compared with the previous risk of 2\%. Similarly, Kano et al. described 996 AVM patients treated with SRS who had an annual hemorrhage risk of $3.4 \%$ pre-SRS versus $1.3 \%$ post-SRS. However, these reports were predominately focused on small AVMs. ${ }^{15,44}$ Karlsson et al. documented an annual hemorrhage risk of $7 \%$ in patients post-SRS with AVMs $>9 \mathrm{ml}$, which appears similar to the rate in this report. ${ }^{17}$ Kano et al. also noted a $36 \%$ rate of hemorrhage at 10 years after SRS. ${ }^{15}$ Our $39 \%$ mortality rate in patients who had a hemorrhage was higher than the accepted risk of 10\%-30\% mortality per hemorrhage..$^{29}$ The high rates of hemorrhage and hemorrhage-related mortality reinforce the high-risk nature of these large AVMs.

\section{Conclusions}

The ideal treatment for large AVMs is unknown, but VS-SRS is an option for initial treatment. Decreasing the AVM treatment volume per stage to $\leq 8-10 \mathrm{ml}$ allowed for a higher dose per fraction ( $\geq 17 \mathrm{~Gy}$ ) and decreased time to response, as well as increased rates of near obliteration and cure without increasing complications. Obliteration rates of large AVMs remain low, although partial response or near obliteration may expedite safe resection in previously unresectable lesions. Patients should be evaluated for repeat SRS or surgical salvage if there is failure to achieve obliteration at 3 years' follow-up, as many patients will require multimodal treatment for cure.

\section{References}

1. Andrade-Souza YM, Zadeh G, Ramani M, Scora D, Tsao MN, Schwartz ML: Testing the radiosurgery-based arteriovenous malformation score and the modified Spetzler-Martin grading system to predict radiosurgical outcome. J Neurosurg 103:642-648, 2005

2. Back AG, Vollmer D, Zeck O, Shkedy C, Shedden PM: Retrospective analysis of unstaged and staged Gamma Knife surgery with and without preceding embolization for the treatment of arteriovenous malformations. J Neurosurg 109 Suppl:57-64, 2008

3. Blackburn SL, Ashley WW Jr, Rich KM, Simpson JR, Drzymala RE, Ray WZ, et al: Combined endovascular embolization and stereotactic radiosurgery in the treatment of large arteriovenous malformations. J Neurosurg 114:1758-1767, 2011

4. Chung WY, Shiau CY, Wu HM, Liu KD, Guo WY, Wang LW, et al: Staged radiosurgery for extra-large cerebral arteriovenous malformations: method, implementation, and results. J Neurosurg 109 Suppl:65-72, 2008

5. Flickinger JC, Kondziolka D, Lunsford LD, Kassam A, Phuong LK, Liscak R, et al: Development of a model to predict permanent symptomatic postradiosurgery injury for arterio- 
venous malformation patients. Int J Radiat Oncol Biol Phys 46:1143-1148, 2000

6. Flickinger JC, Kondziolka D, Maitz AH, Lunsford LD: An analysis of the dose-response for arteriovenous malformation radiosurgery and other factors affecting obliteration. Radiother Oncol 63:347-354, 2002

7. Flickinger JC, Pollock BE, Kondziolka D, Lunsford LD: A dose-response analysis of arteriovenous malformation obliteration after radiosurgery. Int J Radiat Oncol Biol Phys 36:873-879, 1996

8. Foote KD, Friedman WA, Ellis TL, Bova FJ, Buatti JM, Meeks SL: Salvage retreatment after failure of radiosurgery in patients with arteriovenous malformations. J Neurosurg 98:337-341, 2003

9. Gobin YP, Laurent A, Merienne L, Schlienger M, Aymard A, Houdart E, et al: Treatment of brain arteriovenous malformations by embolization and radiosurgery. J Neurosurg 85:19-28, 1996

10. Gross BA, Du R: Natural history of cerebral arteriovenous malformations: a meta-analysis. J Neurosurg 118:437-443, 2013

11. Hamilton MG, Spetzler RF: The prospective application of a grading system for arteriovenous malformations. Neurosurgery 34:2-7, 1994

12. Hattangadi JA, Chapman PH, Bussière MR, Niemierko A, Ogilvy CS, Rowell A, et al: Planned two-fraction proton beam stereotactic radiosurgery for high-risk inoperable cerebral arteriovenous malformations. Int J Radiat Oncol Biol Phys 83:533-541, 2012

13. Kano H, Kondziolka D, Flickinger JC, Park KJ, Parry PV, Yang HC, et al: Stereotactic radiosurgery for arteriovenous malformations, Part 6: multistaged volumetric management of large arteriovenous malformations. J Neurosurg 116:5465,2012

14. Kano H, Kondziolka D, Flickinger JC, Yang HC, Flannery TJ, Awan NR, et al: Stereotactic radiosurgery for arteriovenous malformations, Part 3: outcome predictors and risks after repeat radiosurgery. J Neurosurg 116:21-32, 2012

15. Kano H, Kondziolka D, Flickinger JC, Yang HC, Park KJ, Flannery TJ, et al: Aneurysms increase the risk of rebleeding after stereotactic radiosurgery for hemorrhagic arteriovenous malformations. Stroke 43:2586-2591, 2012

16. Kano H, Lunsford LD, Flickinger JC, Yang HC, Flannery TJ, Awan NR, et al: Stereotactic radiosurgery for arteriovenous malformations, Part 1: management of Spetzler-Martin Grade I and II arteriovenous malformations. J Neurosurg 116:11-20, 2012

17. Karlsson B, Jokura H, Yamamoto M, Söderman M, Lax I: Is repeated radiosurgery an alternative to staged radiosurgery for very large brain arteriovenous malformations? J Neurosurg 107:740-744, 2007

18. Karlsson B, Lindquist C, Steiner L: Prediction of obliteration after gamma knife surgery for cerebral arteriovenous malformations. Neurosurgery 40:425-431, 1997

19. Kim HY, Chang WS, Kim DJ, Lee JW, Chang JW, Kim DI, et al: Gamma Knife surgery for large cerebral arteriovenous malformations. J Neurosurg 113 Suppl:2-8, 2010

20. Koltz MT, Polifka AJ, Saltos A, Slawson RG, Kwok Y, Aldrich EF, et al: Long-term outcome of Gamma Knife stereotactic radiosurgery for arteriovenous malformations graded by the Spetzler-Martin classification. J Neurosurg 118:74-83, 2013

21. Lawton MT: Spetzler-Martin Grade III arteriovenous malformations: surgical results and a modification of the grading scale. Neurosurgery 52:740-749, 2003

22. Lawton MT, Kim H, McCulloch CE, Mikhak B, Young WL: A supplementary grading scale for selecting patients with brain arteriovenous malformations for surgery. Neurosurgery 66:702-713, 2010
23. Mathis JA, Barr JD, Horton JA, Jungreis CA, Lunsford LD, Kondziolka DS, et al: The efficacy of particulate embolization combined with stereotactic radiosurgery for treatment of large arteriovenous malformations of the brain. AJNR Am J Neuroradiol 16:299-306, 1995

24. Miyawaki L, Dowd C, Wara W, Goldsmith B, Albright N, Gutin P, et al: Five year results of LINAC radiosurgery for arteriovenous malformations: outcome for large AVMS. Int J Radiat Oncol Biol Phys 44:1089-1106, 1999

25. Pan DH, Guo WY, Chung WY, Shiau CY, Chang YC, Wang LW: Gamma knife radiosurgery as a single treatment modality for large cerebral arteriovenous malformations. J Neurosurg 93 (3 Suppl 3): 113-119, 2000

26. Petti PL, Coleman J, McDermott M, Smith V, Larson DA: Anatomic landmarks versus fiducials for volume-staged gamma knife radiosurgery for large arteriovenous malformations. Int J Radiat Oncol Biol Phys 67:1578-1585, 2007

27. Pollock BE, Flickinger JC: Modification of the radiosurgerybased arteriovenous malformation grading system. Neurosurgery 63:239-243, 2008

28. Pollock BE, Flickinger JC: A proposed radiosurgery-based grading system for arteriovenous malformations. J Neurosurg 96:79-85, 2002

29. Pollock BE, Flickinger JC, Lunsford LD, Bissonette DJ, Kondziolka D: Factors that predict the bleeding risk of cerebral arteriovenous malformations. Stroke 27:1-6, 1996

30. Pollock BE, Flickinger JC, Lunsford LD, Maitz A, Kondziolka D: Factors associated with successful arteriovenous malformation radiosurgery. Neurosurgery 42:1239-1247, 1998

31. Pollock BE, Kondziolka D, Flickinger JC, Patel AK, Bissonette DJ, Lunsford LD: Magnetic resonance imaging: an accurate method to evaluate arteriovenous malformations after stereotactic radiosurgery. J Neurosurg 85:1044-1049, 1996

32. Pollock BE, Kline RW, Stafford SL, Foote RL, Schomberg PJ: The rationale and technique of staged-volume arteriovenous malformation radiosurgery. Int J Radiat Oncol Biol Phys 48:817-824, 2000

33. Sanchez-Mejia RO, McDermott MW, Tan J, Kim H, Young WL, Lawton MT: Radiosurgery facilitates resection of brain arteriovenous malformations and reduces surgical morbidity. Neurosurgery 64:231-240, 2009

34. Silander H, Pellettieri L, Enblad P, Montelius A, Grusell E, Vallhagen-Dahlgren $\mathrm{C}$, et al: Fractionated, stereotactic proton beam treatment of cerebral arteriovenous malformations. Acta Neurol Scand 109:85-90, 2004

35. Sirin S, Kondziolka D, Niranjan A, Flickinger JC, Maitz AH, Lunsford LD: Prospective staged volume radiosurgery for large arteriovenous malformations: indications and outcomes in otherwise untreatable patients. Neurosurgery 58:17-27, 2006

36. Spetzler RF, Martin NA: A proposed grading system for arteriovenous malformations. J Neurosurg 65:476-483, 1986

37. Starke RM, Yen CP, Ding D, Sheehan JP: A practical grading scale for predicting outcome after radiosurgery for arteriovenous malformations: analysis of 1012 treated patients. J Neurosurg 119:981-987, 2013

38. Stefani MA, Porter PJ, terBrugge KG, Montanera W, Willinsky RA, Wallace MC: Large and deep brain arteriovenous malformations are associated with risk of future hemorrhage. Stroke 33:1220-1224, 2002

39. Vernimmen FJ, Slabbert JP, Wilson JA, Fredericks S, Melvill R: Stereotactic proton beam therapy for intracranial arteriovenous malformations. Int J Radiat Oncol Biol Phys 62:44-52, 2005

40. Veznedaroglu E, Andrews DW, Benitez RP, Downes MB, Werner-Wasik M, Rosenstock J, et al: Fractionated stereotactic radiotherapy for the treatment of large arteriovenous 
malformations with or without previous partial embolization. Neurosurgery 55:519-531, 2004

41. Veznedaroglu E, Andrews DW, Benitez RP, Downes MB, Werner-Wasik M, Rosenstock J, et al: Fractionated stereotactic radiotherapy for the treatment of large arteriovenous malformations with or without previous partial embolization. Neurosurgery 62 (2 Suppl 2):763-775, 2008

42. Yamamoto M, Akabane A, Matsumaru Y, Higuchi Y, Kasuya H, Urakawa Y: Long-term follow-up results of intentional 2-stage Gamma Knife surgery with an interval of at least 3 years for arteriovenous malformations larger than $10 \mathrm{~cm}^{3}$. J Neurosurg 117 Suppl:126-134, 2012

43. Yang SY, Kim DG, Chung HT, Paek SH, Park JH, Han DH: Radiosurgery for large cerebral arteriovenous malformations. Acta Neurochir (Wien) 151:113-124, 2009

44. Yen CP, Schlesinger D, Sheehan JP: Natural history of cerebral arteriovenous malformations and the risk of hemorrhage after radiosurgery. Prog Neurol Surg 27:5-21, 2013

\section{Author Contributions}

Conception and design: Seymour, Sneed, Gupta, Lawton, McDer- mott. Acquisition of data: Seymour, Sneed, Young. Analysis and interpretation of data: Seymour, Sneed. Drafting the article: Seymour, Sneed. Critically revising the article: all authors. Reviewed submitted version of manuscript: Seymour, Sneed, Molinaro, Dowd, Halbach, Higashida, McDermott. Approved the final version of the manuscript on behalf of all authors: Seymour. Statistical analysis: Seymour, Sneed. Study supervision: Sneed, McDermott.

\section{Supplemental Information \\ Previous Presentation}

Portions of this work were presented in abstract and oral presentation forms at the 17th Leksell Gamma Knife Society Meeting held in New York on May 11-15, 2014, and the 11th International Stereotactic Radiosurgery Society Meeting held in Toronto, Ontario, Canada, on June 16-20, 2013.

\section{Correspondence}

Zachary A. Seymour, Department of Radiation Oncology, University of California, San Francisco, 400 Parnassus Ave., San Francisco, CA 94143. email: seymourz@radonc.ucsf.edu. 